\title{
Windows of opportunity: thresholds to mangrove seedling establishment on tidal flats
}

\author{
Thorsten Balke $^{1, *}$, Tjeerd J. Bouma ${ }^{1,2}$, Erik M. Horstman ${ }^{3}$, Edward L. Webb ${ }^{4}$, \\ Paul L. A. Erftemeijer ${ }^{1,5}$, Peter M. J. Herman ${ }^{2}$ \\ ${ }^{1}$ Deltares, PO Box 177, 2600 MH Delft, The Netherlands \\ ${ }^{2}$ Centre for Estuarine and Marine Ecology, Netherlands Institute of Ecology (NIOO-KNAW), 4400 AC Yerseke, The Netherlands \\ ${ }^{3}$ Department of Water Engineering \& Management, University of Twente, 7500 AE Enschede, The Netherlands \\ ${ }^{4}$ Department of Biological Sciences, National University of Singapore, Singapore 117543 \\ ${ }^{5}$ Present address: Sinclair Knight Merz (SKM), PO Box H615, Perth, Western Australia 6001, Australia
}

\begin{abstract}
Physical processes limiting colonization of bare tidal flats by pioneer mangrove species have commonly been described but not yet quantified. Understanding thresholds to early seedling establishment is critical for successful restoration and management of mangrove forests. We determined how seedling establishment of Avicennia alba Bl. is affected by the combination of increasing hydrodynamic forces and sediment dynamics. As the buoyant propagules of A. alba are dispersed by water, early establishment on bare tidal flats requires propagules to quickly anchor to stay in place. Flume studies and field observations showed that 3 thresholds have to be passed until the seedling is successfully established: (1) stranded propagules need an inundation-free period to rapidly develop roots that are long enough to withstand displacement by flooding, (2) roots need to become long enough to withstand seedling dislodgement by hydrodynamic forces from waves and currents, with the required root length being proportional to the force that needs to be resisted, (3) even longer roots are needed to survive high energy events that cause sheet erosion and can thereby induce seedling dislodgement. This sequence of thresholds implies that establishment of the pioneer mangrove species $A$. alba requires a suitable window of opportunity to pass all thresholds and underlines the importance of rapid root expansion as a crucial pioneer trait for the species.
\end{abstract}

KEY WORDS: Avicennia · Colonization · Flume · Pioneer - Mangrove restoration - Seedling establishment $\cdot$ Succession $\cdot$ Threshold

Resale or republication not permitted without written consent of the publisher

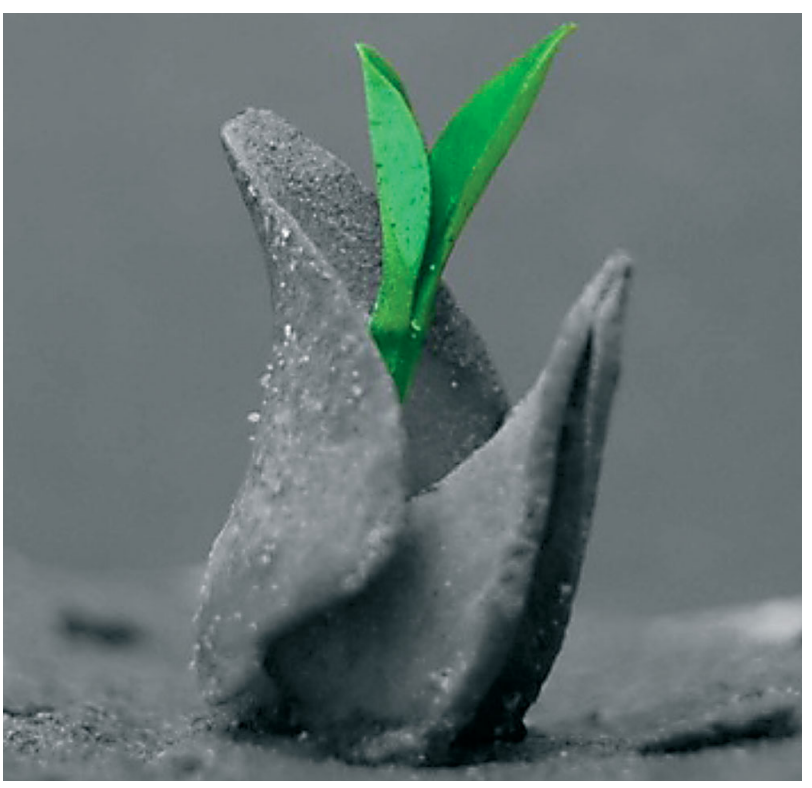

This Avicennia alba seedling must cross 3 definable rootlength thresholds in order to become successfully established.

Image: Thorsten Balke

\section{INTRODUCTION}

Mangroves are rapidly declining worldwide, with the largest total loss (1900 million hectares) occurring in Asia from 1980 to 2005 (Duke et al. 2007, FAO 2007). Once destroyed, restoration of mangroves along the coast is difficult (Erftemeijer \& Lewis 2000, Alongi 2002) unless conditions are favorable (Field 1998, Lugo 1998). Similar problems in restoration have been reported for other coastal vegetation such 
as salt marshes (e.g. Wolters et al. 2005) and seagrass beds (e.g. Van Katwijk et al. 2009). The latter implies that there can be thresholds for seedling establishment on bare tidal flats that must be surpassed for successful colonization. If these thresholds are related to disturbance varying in space and time, seedling establishment requires windows of opportunity where disturbance is low or absent (Romme et al. 1998, Proisy et al. 2009). There is a general lack of mechanistic understanding of processes that cause thresholds to seedling establishment of coastal pioneer vegetations (Bouma et al. 2009a, Friess et al. 2011). Generating a mechanistic understanding of the thresholds that limit colonization of bare tidal flats by mangroves is a key to identifying boundary conditions that offer the window of opportunity for mangrove establishment. This is of critical importance for mangrove management, e.g. as a decision tool to determine where proactive versus passive restoration should be attempted.

Avicennia is the most widespread genus of mangrove pioneer trees, colonizing bare tidal flats of tropical regions around the world (see Osborne \& Berjak 1997 for A. marina in Africa; Lee et al. 1996, Panapitukkul et al. 1998 for A. alba in SE Asia; Marchand et al. 2004, Proisy et al. 2009 for A. germinans in South America; Clarke 1993 for A. marina in Australia). When conditions are favorable, instantaneous colonization of tens of hectares by Avicennia can take place in a few days as reported for migrating mud banks in South America (Proisy et al. 2009). Avicennia seedlings are well adapted to the harsh intertidal environment where flooding and anoxic soils limit plant growth (Clarke 1993, Osborne \& Berjak 1997), and these species produce relatively large numbers of cryptoviviparous propagules (i.e. only partly germinating while still on the tree) that are distributed by the tide (Panapitukkul et al. 1998) and establish rapidly after stranding (Osborne \& Berjak 1997). Although the embryo is always developmentally active, recalcitrancy (hence, moisture) is likely to control germination after release (Osborne \& Berjak 1997, Le Tam et al. 2004). Up to 6 additional root primordia remain suppressed during the first stranding, enabling Avicennia propagules to anchor in a second or third stranding (Osborne \& Berjak 1997).

Earlier studies on mangrove establishment mostly focused on phenology of the parent tree, buoyancy times of propagules or survival of seedlings in the sapling stage that were already successfully established (Di Nitto et al. 2008, Krauss et al. 2008). Thampanya et al. (2002) demonstrated indirectly that colonizers such as Avicennia alba and Sonneratia alba have greater survival rates at exposed sites with high hydrodynamic energy than Rhizophora sp. However, still little is known about how hydrodynamic and geomorphological processes may hamper the initial establishment of stranded Avicennia propagules.

In this study we quantify the thresholds to initial seedling establishment by a combination of flume experiments and field measurements. For different developmental phases of the very young seedling, we determined which factor was most critical for survival and how this factor changed with root development.

\section{MATERIALS AND METHODS}

\section{Seedling growth conditions}

Propagules of Avicennia alba were collected from Singapore mangroves and brought to the Netherlands within $48 \mathrm{~h}$ in a moist container. They were cultivated immediately in a climate room, which was held at $30^{\circ} \mathrm{C}$ and provided an average of $12 \mathrm{~h} \mathrm{~d}^{-1}$ of $550 \mu \mathrm{mol} \mathrm{m}{ }^{-2} \mathrm{~s}^{-1}$ photosynthetically active radiation (PAR), on arrival. The experiment was completed $13 \mathrm{~d}$ after receipt and immediate planting. Propagules were laid on top of marine sand in individual PVC pipes with dimensions of $150 \mathrm{~mm}$ height and $120 \mathrm{~mm}$ diameter, which had open bottoms and were lined with polyethylene bags. The sand was kept waterlogged throughout the experiment. This setup simulated natural stranding on the tidal flat, free from tidal inundation. The pot design allowed us to measure in a flume both the hydrodynamic stress and sediment disturbance that seedlings could withstand before getting dislodged (see next section for details). Seedcoats were already shed at the time of planting, and any root primordia were $<5 \mathrm{~mm}$ in length. For simplification, hereafter all propagules showing their first roots are called seedlings. From Days 5 to 13 after planting, 10 pots were randomly selected each day and subjected to the flume experiment. Root growth was measured after the flume experiments.

\section{Flume experiments on seedling dislodgment}

The flume consisted of a $17.5 \mathrm{~m}$ long and $0.6 \mathrm{~m}$ wide oval racetrack that could produce currents and waves (Bouma et al. 2009b). A double bottom in the test section allowed the cut PVC pipes filled with sediment to be inserted flush with the flume bed, leaving only the seedling exposed (Fig. 1). No significant scouring was observed. Flume water depth was 


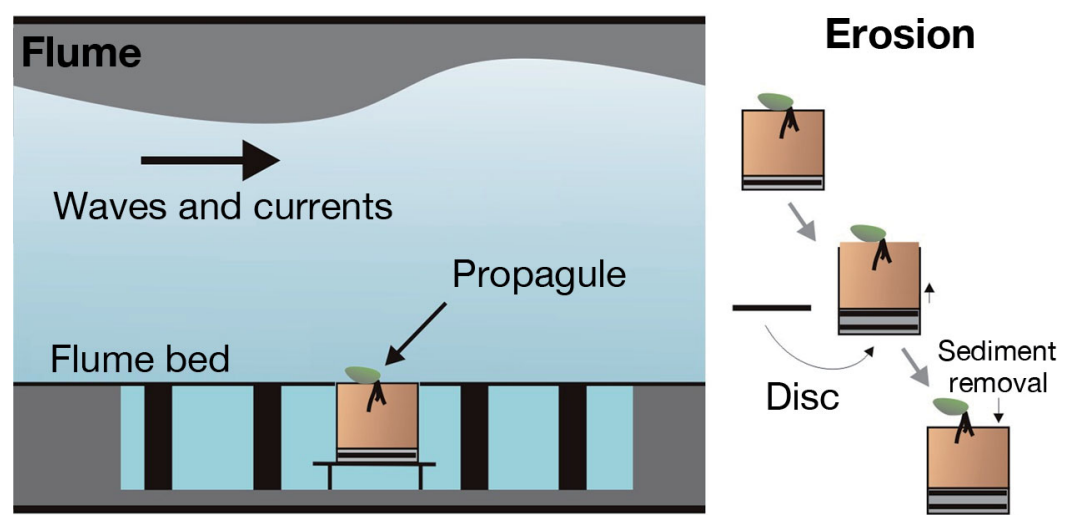

Fig. 1. Avicennia alba. Flume setup showing (bronze-coloured area) pots made of PVC pipe that were filled with marine sand, contained the planted propagules/seedlings and lowered to the second bottom of the flume so that the top of the sand was flush with the level of the flume bed. Erosion was mimicked by inserting discs from underneath to lift the 'sediment core' inside the PVC pipe, thereafter excess sediment was removed from around the seedling

maintained at $32 \mathrm{~cm}$. A constant current of $3.5 \mathrm{~cm} \mathrm{~s}^{-1}$ was applied with a conveyor belt, and wave energy was varied by adjusting the wave paddle. Maximum bed shear stress was calculated from pressure sensor (GE Druck PTX1830) measurements, as a measure for the hydrodynamic forcing on the seedling at the bottom of the flume. The experimental conditions allowed us to apply Jonsson's (1966) formula to calculate maximum bed shear stress due to waves. Additional bed shear stresses due to the slow current in the flume were quantified by calculating the apparent roughness height for the flume bottom for waves propagating in the same direction as the current (van Rijn 1993). Time-averaged total bed shear stress was subsequently calculated by adding both components. A reduction factor for the currentinduced bed shear stress due to the presence of the waves was applied (van Rijn 2008). Maximum bed shear stress of waves and current have been derived by adding the total time-averaged bed shear stress and maximum shear stress under waves, as both have the same direction (Soulsby 1997). Equations used are explained in Appendix 1.

Three different tests were carried out in the flume. (1) The pots were slowly submerged to test whether the seedlings would float up. (2) If the seedlings stayed in place, bed shear stress was increased from 0.17 to $0.52 \mathrm{~N} \mathrm{~m}^{-2}$ in a maximum of 13 increments with each increment lasting approximately $2 \mathrm{~min}$. (3) For seedlings that resisted the maximum bottom shear stress of $0.52 \mathrm{~N} \mathrm{~m}^{-2}$ in Test 2, we determined their critical vertical erosion, which was defined as the amount of sediment that needed to be removed from around a seedling in order to dislodge it. The critical erosion at dislodgement was determined by raising the sediment incrementally by placing PVC discs of $3 \mathrm{~mm}$ thickness underneath the pipe. Sediment at the top of the PVC pipe was gently removed by hand to keep the sediment level flush with the flume bottom. After each step-wise sediment removal, seedlings were exposed to a maximum bed shear stress of $0.27 \mathrm{~N}$ $\mathrm{m}^{-2}$ (i.e. wave height of $6 \mathrm{~cm}$ ). This protocol was repeated until dislodgement occurred. After dislodgement, root length of the longest, last dislodged root was measured. We observed no root snapping during this experiment that would confound root length measurements.

\section{Seedling dislodgement with drag scale}

To corroborate the flume experiments, we conducted field measurements to determine both the minimum root length that could be observed on established seedlings in the field and the forces needed to remove recently anchored seedlings from the mudflat. Avicennia propagules/seedlings were randomly selected within survey quadrats at 3 contrasting locations (along inundation gradient) in the Mandai mangrove forest in Singapore. A spring scale with $20 \%$ tare error and $1 \mathrm{~g}$ reading error (Pesola Medio-Line 40300 with drag pointer) was clipped to the top of each propagule/seedling and carefully pulled upward until dislodgement, and the force needed to dislodge the seedlings was read directly from the scale. If the propagule/seedling was not anchored yet, i.e. there was no root penetration into the substrate, no value was recorded. The frictional force of the attached drag pointer $(40 \mathrm{~g} 0.4 \mathrm{~N}$, see www.pesola.com) was accounted for in the analysis. The weight of the seedling ( 1 to $3 \mathrm{~g} \sim 0.01$ to $0.03 \mathrm{~N}$ ) was deducted from the pulling force. Maximum root length was measured for all dislodged seedlings.

As we did not find seedlings with root lengths below $2.5 \mathrm{~cm}$, we planted small propagules in pots with waterlogged mangrove mud. After 2 to $3 \mathrm{~d}$ of establishment, the same pulling test was carried out on these small seedlings. Snapping of roots did not occur due to the soft substrate and the short roots. 


\section{RESULTS}

\section{Seedling root growth}

The first root primordia were visible $2 \mathrm{~d}$ after simulated stranding, and on the third day the maximum root length was $1 \mathrm{~cm}$. At least $75 \%$ of all propagules had developed visible roots by Day 4 . On Day 6, the first seedlings were found to be erect due to extension of the hypocotyl. On Day $8,24.5 \%$ of all seedlings had expanded cotyledons. Root length increased linearly from Days 5 to 13 after planting (Fig. 2). Seedlings developed 1 to 5 roots over the course of the experiments.

\section{Flume experiments on seedling dislodgement}

On average, a minimum root length of $2 \mathrm{~cm}$ was required to prevent the buoyant propagule from floating up when inundated, without hydrodynamic force from waves or currents (Fig. 3). Until the last day (Day 13), seedlings showed buoyancy after dislodgment. Seedlings with a maximum root length between 2 and $4 \mathrm{~cm}$ were sensitive to dislodgement due to wave action. The bed shear stress that caused seedling dislodgment was linearly related to the length of the longest root of the seedling (Fig. 3). Above a maximum root length of $4 \mathrm{~cm}$ (Fig. 3), seedlings could no longer be dislodged by the maximum bottom shear stress that we could impose in the flume, which was determined by water height and wave paddle design. In our study, this root length was reached on average after $8 \mathrm{~d}$ (Fig. 2). Critical erosion at dislodgement was linearly correlated with maximum root length (Fig. 4); $4 \mathrm{~cm}$ of the longest root

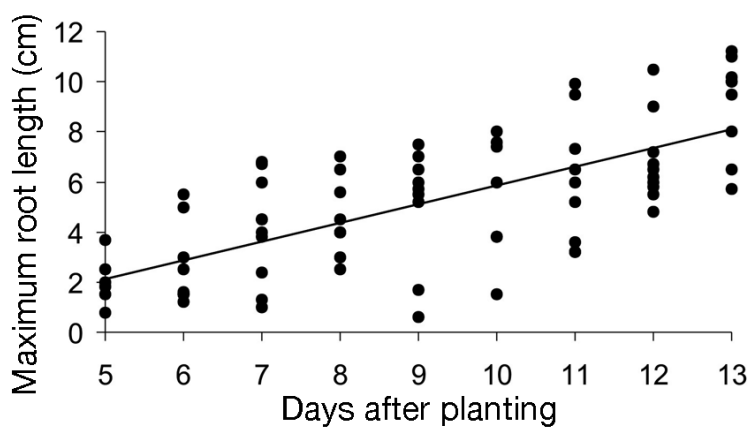

Fig. 2. Avicennia alba. Maximum root length $\left(R_{\max } \mathrm{cm}\right)$ as a function of time since stranding of the propagule $(T ; d)$. Root growth was measured on a maximum of 10 harvested seedlings per day $(\mathrm{N}=76$, nongerminated propagules were excluded). The maximum root length could be characterized

by the linear regression: $R_{\max }=0.75 \times T-1.62\left(\mathrm{R}^{2}=0.49\right)$

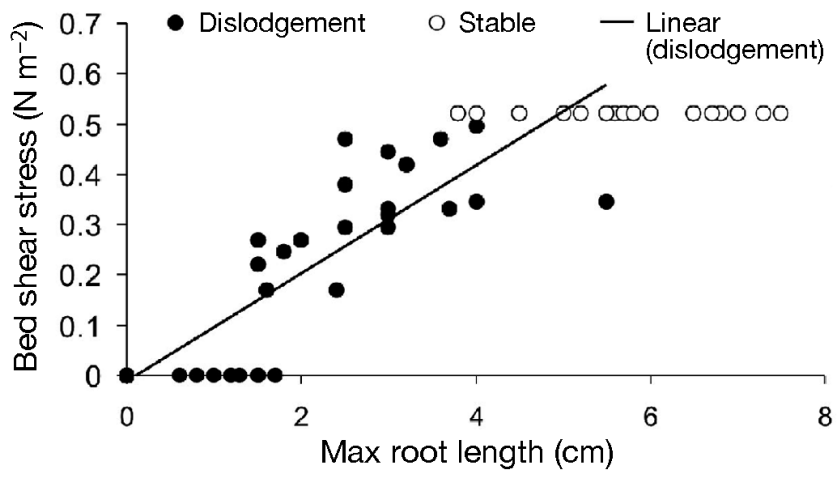

Fig. 3. Avicennia alba. The hydrodynamic force expressed as bed shear stress $\left(\tau_{\mathrm{b} i} \mathrm{~N} \mathrm{~m}^{-2}\right)$ that can be resisted before seedlings (fixed seedlings: $\mathrm{N}=28$, dislodged seedlings: $\mathrm{N}=$ $42)$ with maximum root length $\left(R_{\max }, \mathrm{cm}\right)$ were dislodged. Seedlings with $\leq 2 \mathrm{~cm}$ roots would float up when flooded, even in the absence of any waves or current. The bed shear stress experienced by seedlings at the flume bottom at the moment of dislodgment increased linearly with maximum root length: $\tau_{\mathrm{b}}=0.1071 \times R_{\max }-0.0113\left(\mathrm{R}^{2}=0.75\right)$. Once the maximum root length exceeded $4 \mathrm{~cm}$, all seedlings were stable and could resist the highest level of bed shear stress applied in the flume

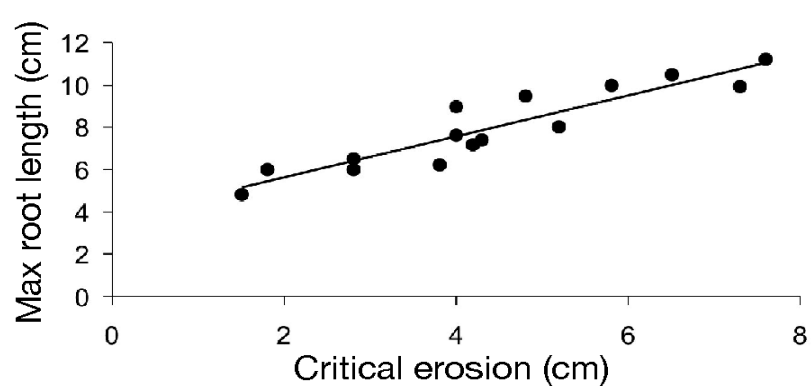

Fig. 4. Avicennia alba. The critical vertical erosion $\left(E_{\text {criti }} \mathrm{cm}\right)$ that needs to be surpassed to dislodge seedlings $(\mathrm{N}=15)$ of different root lengths $\left(R_{\max } i \mathrm{~cm}\right)$. For a constant bed shear stress of $0.27 \mathrm{~N} \mathrm{~m}^{-2}$, the maximum root length is linearly correlated with the critical vertical erosion that was mimicked in the flume: $E_{\text {crit }}=0.93 \times R_{\max }+3.79\left(\mathrm{R}^{2}=0.79\right)$

needed to remain below ground in order to keep the seedling in place.

\section{Seedling dislodgement with drag scale}

Based on the flume results, which demonstrated the important role that roots have in seedling survival (Figs. $3 \& 4$ ), we measured the minimal root length that can be observed on established seedlings in the field and how root length affects the (vertical) force seedlings can resist before uprooting. All naturally established seedlings were found to have at least 1 root with a length greater than $2.5 \mathrm{~cm}$ (Fig. 5). For 


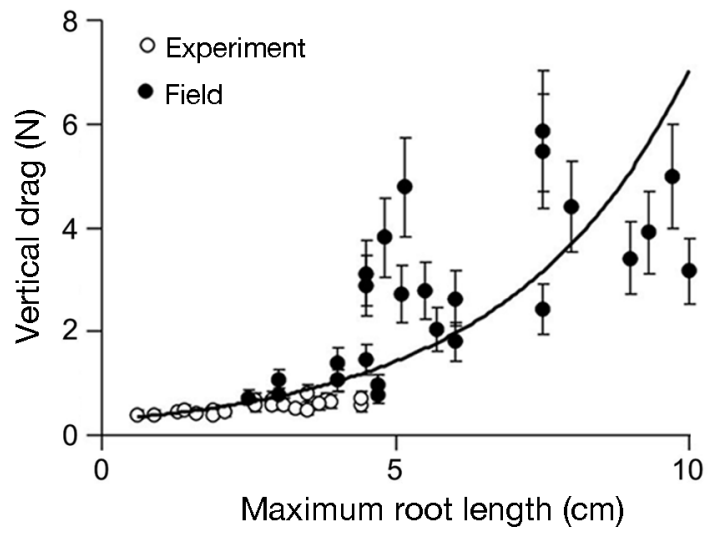

Fig. 5. Avicennia alba. The critical vertical drag force needed for seedling (field: $\mathrm{N}=26$, planted: $\mathrm{N}=24$ ) dislodgement $\left(F_{\text {criti }} \mathrm{N}\right)$ is correlated exponentially to the maximum root length $\left(R_{\max } ; \mathrm{cm}\right): F_{\text {crit }}=0.2877 \mathrm{e}^{0.3196\left(R_{\max }\right)}\left(\mathrm{R}^{2}=0.73\right)$. Error bars represent the tare error of $20 \%$ of the spring scale. Especially for small seedlings with maximum root lengths of $<5 \mathrm{~cm}$, a small increase in root length is important to enhance anchorage. As there were no field seedlings with a maximum root length $\leq 3 \mathrm{~cm}$, we planted seedlings in pots filled with mangrove mud ('experiment')

both experimentally planted and in situ seedlings, the force needed to vertically pull a seedling (root anchorage plus seedling weight) out of the soil increased exponentially with maximum root length (Fig. 5). Thus, the length of the longest root proved to be a good proxy for anchorage strength, both in the flume (Figs. $3 \& 4$ ) and in the drag scale experiment (Fig. 5). A small increase in root length leads to a large increase in stability during the earliest seedling stage (i.e. root $<5 \mathrm{~cm}$ ). The exponential increase of the drag scale field data compared with the linear relationship obtained in the flume might be explained by increased soil compaction with depth for the deeper rooting seedlings in the field and presence of fine roots for seedlings with approximately $>5 \mathrm{~cm}$ maximum root length. Resolving this requires further studies in the future.

\section{DISCUSSION}

\section{Thresholds to early seedling establishment and windows of opportunity}

Despite the growing concern for global mangrove loss and the interest in mangrove dynamics and establishment (Krauss et al. 2008), similar to those for salt marshes and seagrass beds (Bouma et al. 2009a), a general understanding of the mechanistic processes underlying the apparent thresholds to early establishment of pioneer species is lacking (Di Nitto et al. 2008). To our knowledge the present study is the first to provide a mechanistic insight on how disturbance by hydrodynamic forces and associated sediment dynamics defines thresholds to Avicennia colonization on a tidal flat. Based on our results, we distinguish 3 thresholds during seedling establishment (Fig. 6). First, anchorage of A. alba propagules requires a minimum period during which it is free from inundation after stranding. Second, root growth has to surpass a minimum length to withstand disturbance of hydrodynamic forces by waves and currents imposed on the seedlings. Third, root length needs to be sufficient to resist disturbances from removal of sediment around the seedling, which can be caused by sediment mixing and/or sheet erosion (Fig. 6). The latter is important for bare mudflat colonization, as previous research has demonstrated that physical mixing of the upper sediment layer on mudflats is substantial and the mixing depth decreases in a landward direction (e.g. 4 to $30 \mathrm{~cm}$ over a $100 \mathrm{~d}$ period for a Brazilian mangrove, Smoak \& Patchineelam 1999). Less disturbance can be expected inside the forest due to root structures attenuating hydrodynamic energy. By using non-cohesive sediments in the flume we show that exceeding the critical bed shear stress for sediment movement (cf. Soulsby 1997) without dislodging the propagule is possible, hence supporting the existence of the third threshold in which the seedling gets excavated.

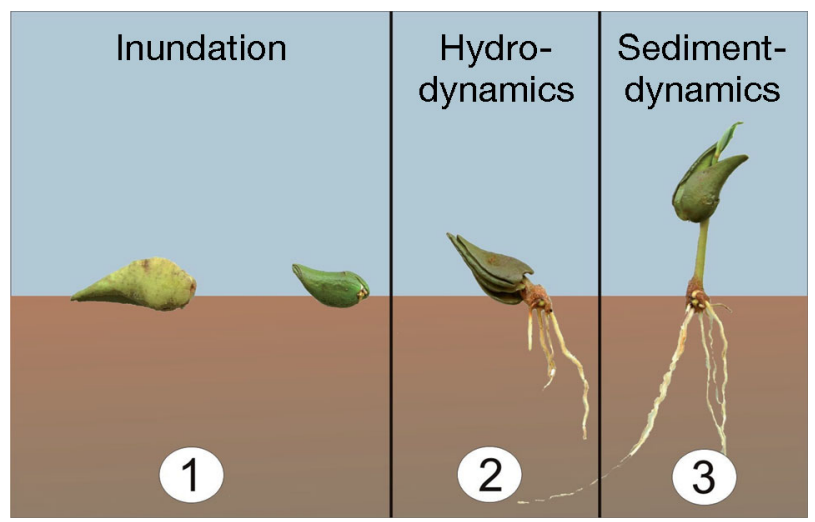

Fig. 6. Avicennia alba. Schematic representation of the 3 thresholds that need to be reached during establishment of an Avicennia seedling. Magnitude of disturbance increases from left to right. After the seed coat is shed the propagule starts to put out its roots to anchor in the sediment. (1) The propagule first has to acquire a minimum root length during an inundation-free period to resist against floating up during tidal inundation. (2) Thereafter, roots need to be long enough to resist forces by wave and currents. (3) After the roots penetrate several centimeters into the sediment, only mixing or erosion of the upper sediment layer can still lead to dislodgement 
Although the mechanisms of early seedling establishment will likely be generally valid, the actual threshold values may also vary depending on local conditions. For example, root extension rate (Fig. 2) can be expected to vary with abiotic conditions such as salinity and temperature (Krauss et al. 2008). The minimal root length needed to withstand floating immediately following stranding, and subsequently to withstand hydrodynamic drag forces (which was in our case $4 \mathrm{~cm}$ ), will be variable depending on factors such as sediment composition and the local wave climate. For example, breaking waves at lower water levels may impose higher forces in the field with longer durations of exposure than we mimicked in the flume. In that case, longer roots would be needed to anchor the seedling. However, cohesive muddy sediments may give more support to the roots than the loose sand used in present experiments, in which case shorter roots could be sufficient.

Being amongst the most successful mangrove colonizers, Avicennia appears to be well adapted to establish on dynamic bare mudflats. That is, Avicennia is able to anchor rapidly, resist hydrodynamic forces from waves and currents within a few days, and then resist sediment movements of the upper sediment layer. The presence of thresholds (i.e. a seedling either has sufficient time to anchor or is dislodged), provides an explanation for observations of colonization of mudflats by Avicennia cohorts (e.g. Proisy et al. 2009), which presumably occurs whenever windows of opportunity open up and propagules are available. Such conditions could occur at neap tides during the fruiting season. Mass establishment of Avicennia may be reflected in even-aged stands of Avicennia on the tidal flat. The mudflat remains bare in front of more mature mangrove stands where thresholds can not be surpassed. The experiments underline the importance of coastal hydrodynamics and resulting sediment dynamics in mangrove regeneration and colonization processes (Fromard et al. 2004). Concurrence of windows of opportunity (e.g. depending on tides and weather) and propagule availability (i.e. fruiting seasons) are likely to be important for colonization success and ecosystem stability.

\section{Implications for application}

The demonstration of thresholds for mangrove seedling establishment implies that gradual change of the drivers (hydrodynamics, sediment dynamics) may cause an abrupt shift in the success of mangrove seedling establishment. Anthropogenic processes that change these drivers (e.g. coastal infrastructure works or increased boat traffic) could affect the boundary conditions for seedling establishment on a mudflat. The present study indicates that the threshold dynamics should be considered when impacts of anthropogenic influences or global change processes are assessed.

Where active reforestation is likely to be limited by disturbance, e.g. in fringing mangroves, consideration of the threshold dynamics can help to increase restoration success. A site is only suitable if (1) the inundation frequency is within acceptable physiological limits for each species (Lewis 2005), (2) the phase of the tidal cycle regularly allows propagules to strand and anchor during windows of opportunity, and (3) the sediment is firm enough to minimize mixing and erosion. As emphasized by Lewis (2005), planting mangroves on any convenient bare mudflat is not wise, as 'there is a reason why mangroves are not already there (...) find out why'. The mechanistic approach we used to identify threshold dynamics for seedling establishment offers an important tool in this process.

Acknowledgements. Research was conducted under Singapore NParks permit number NP/RP936-1. We gratefully acknowledge the NIOO-CEME for the use of the flume and mesocosm facilities and D. Galli for supporting field work in Singapore. Funding was provided by the Singapore-Delft Water Alliance Marine 3 programme, grant number R-264001-024-414, National University of Singapore.

\section{LITERATURE CITED}

Alongi DM (2002) Present state and future of the world's mangrove forests. Environ Conserv 29:331-349

Bouma TJ, Friedrichs M, Klaassen P, van Wesenbeeck BK and others (2009a) Effects of shoot stiffness, shoot size and current velocity on scouring sediment from around seedlings and propagules. Mar Ecol Prog Ser 388: 293-297

Bouma TJ, Friedrichs M, van Wesenbeeck BK, Temmerman S, Graf G, Herman PMJ (2009b) Density-dependent linkage of scale-dependent feedbacks: a flume study on the intertidal macrophyte Spartina anglica. Oikos 118:260-268

> Clarke PJ (1993) Dispersal of grey mangrove (Avicennia marina) propagules in southeastern Australia. Aquat Bot 45:195-204

> Di Nitto D, Dahdouh-Guebas F, Kairo JG, Decleir H, Koedam N (2008) Digital terrain modelling to investigate the effects of sea level rise on mangrove propagule establishment. Mar Ecol Prog Ser 356:175-188

> Duke NC, Meynecke JO, Dittmann S, Ellison AM and others (2007) A world without mangroves? Science 317:41-42

Erftemeijer PLA, Lewis RR III (2000) Planting mangroves on intertidal mudflats: habitat restoration or habitat conversion? In: Sumantakul V, Havanond S, Charoenrak S, Amornsanguansin $\mathrm{J}$ and others (eds) Enhancing coastal 
ecosystem restoration for the 21st century. Proc Region Seminar East Southeast Asian Countries: Ecotone VIII. Royal Forest Department of Thailand, Bangkok, p 156-165

FAO (Food and Agriculture Organization) (2007) The world's mangroves 1950-2005. FAO For Pap 153

Field CD (1998) Rehabilitation of mangrove ecosystems: an overview. Mar Pollut Bull 37:383-392

Friess DA, Krauss KW, Horstman EM, Balke T, Bouma TJ, Galli D, Webb EL (2011) Are all intertidal wetlands naturally created equal? Bottlenecks, thresholds and knowledge gaps to mangrove and saltmarsh ecosystems. Biol Rev. doi:10.1111/j.1469-185X.2011.00198.x

Fromard F, Vega C, Proisy C (2004) Half a century of dynamic coastal change affecting mangrove shorelines of French Guiana. A case study based on remote sensing data analyses and field surveys. Mar Geol 208:265-280

Jonsson IG (1966) Wave boundary layers and friction factors. Proc 10th Int Conf Coastal Eng, Vol 1. American Society of Civil Engineers, New York, NY, p 127-148

Krauss KW, Lovelock CE, McKee KL, López-Hoffman L, Ewe SML, Sousa WP (2008) Environmental drivers in mangrove establishment and early development: a review. Aquat Bot 89:105-127

Le Tam VT, Hong TD, Ellis RH, Ngoc-Tam BT (2004) Seed storage of Avicennia alba Bl. Seed Sci Technol 32:531-536

Lee SK, Tan WH, Havanond S (1996) Regeneration and colonisation of mangrove on clay-filled reclaimed land in Singapore. Hydrobiologia 319:23-35

Lewis RR III (2005) Ecological engineering for successful management and restoration of mangrove forests. Ecol Eng 24:403-418

Lugo AE (1998) Mangrove forests: a tough system to invade but an easy one to rehabilitate. Mar Pollut Bull 37:427-430

Marchand C, Baltzer F, Lallier-Vergès E, Albéric P (2004) Pore-water chemistry in mangrove sediments: relationship with species composition and developmental stages (French Guiana). Mar Geol 208:361-381

Osborne DJ, Berjak P (1997) The making of mangroves: the remarkable pioneering role played by seeds of Avicennia marina. Endeavour 21:143-147

- Panapitukkul N, Duarte CM, Thampanya U, Kheowvongsri $\mathrm{P}$ and others (1998) Mangrove colonization: mangrove progression over the growing Pak Phanang (SE Thailand) mud flat. Estuar Coast Shelf Sci 47:51-61

> Proisy C, Gratiot N, Anthony EJ, Gardel A, Fromard F, Heuret P (2009) Mud bank colonization by opportunistic mangroves: a case study from French Guiana using lidar data. Cont Shelf Res 29:632-641

Romme WH, Everham EH, Frelich LE, Moritz MA, Sparks RE (1998) Are large, infrequent disturbances qualitatively different from small, frequent disturbances? Ecosystems 1:524-534

Smoak JM, Patchineelam SR (1999) Sediment mixing and accumulation in a mangrove ecosystem: evidence from 210Pb, 234Th and 7Be. Mangroves Salt Marshes 3:17-27

Soulsby RL (1997) Dynamics of marine sands. Thomas Telford, London

> Thampanya U, Vermaat JE, Duarte CM (2002) Colonization success of common Thai mangrove species as a function of shelter from water movement. Mar Ecol Prog Ser 237: 111-120

van Katwijk MM, Bos AR, de Jonge VN, Hanssen LSAM, Hermus DCR, de Jong DJ (2009) Guidelines for seagrass restoration: importance of habitat selection and donor population, spreading of risks, and ecosystem engineering effects. Mar Pollut Bull 58:179-188

van Rijn LC (1993) Principles of sediment transport in rivers, estuaries and coastal seas, Part I. Aqua Publications, Blokzijl

van Rijn LC (2008) Principles of fluid flow and surface waves in rivers, estuaries, seas and oceans, 2nd edn. Aqua Publications, Blokzijl

> Wolters M, Bakker JP, Bertness MD, Jefferies RL, Möller I (2005) Saltmarsh erosion and restoration in south-east England: squeezing the evidence requires realignment. J Appl Ecol 42:844-851 
Appendix 1. Calculation of bed shear stresses in the flume

The flume used for the experiments described in this paper consisted of a $17.5 \mathrm{~m}$ long and $0.6 \mathrm{~m}$ wide oval racetrack that can produce currents and waves simultaneously. During this study the water depth was maintained at $32 \mathrm{~cm}$, a constant current of $3.5 \mathrm{~cm} \mathrm{~s}^{-1}$ was applied with a conveyor belt and wave heights were varied by adjusting the frequency of the wave paddle. Maximum bed shear stress was calculated from pressure sensor measurements (sampled at $25 \mathrm{~Hz}$ ). This pressure signal was first translated in water depths. From these water level fluctuations, wave heights and periods could be derived by simple signal analysis. The calculation of maximum bed shear stresses from the combined action of these waves and the current are explained by summarizing the equations applied. First is an explanation of the calculation of shear stresses under waves using linear wave theory, which was valid in our experiments. Subsequently, shear stresses under a steady current are calculated and finally both components are combined.

\section{Bed shear stresses under waves}

As stated, wave heights $(H)$, water depths $(h)$ and wave periods $(T)$ are predefined in the flume. We show step by step how to calculate the bed shear stress due to waves from these basic parameters.

Wavelength. According to linear wave theory, wavelengths $(L)$ can be calculated as follows from the dispersion relationship:

$$
\omega^{2}=g k \tanh k h
$$

where $\omega$ represents the angular frequency $(2 \pi / T), g$ the gravitational acceleration constant and $k$ the wave number $(2 \pi / L)$. This dispersion relation can be rewritten as:

$$
L=L_{0} \tanh \frac{2 \pi h}{L} \text { with } L_{0}=\frac{g T^{2}}{2 \pi}
$$

This formula cannot be solved directly and needs an iterative solution procedure. In order to calculate $L, L_{0}$ was used as a first estimate of the wavelength; hence $L$ on the right-hand side of the equation can be substituted by $L_{0}$. A second estimate of the wavelength (i.e. $L_{1}$ ) can be calculated. This value can be substituted into the righthand side of the equation again (note not to substitute $L_{0}$ but only $L$ ) to calculate another new value of the wavelength $\left(L_{2}\right)$. This procedure can then be repeated until subsequent calculations of the wavelength show a difference of $<1 \%$.

The non-linearity of observed waves can be expressed by the Ursell number $\left(U_{\mathrm{r}}\right)$ :

$$
U_{\mathrm{r}}=\frac{H L^{2}}{h^{3}}
$$

In general, when $U_{\mathrm{r}}>15$, non-linear wave theory is assumed to be more reliable. For all of our wave conditions, the Ursell number was below 15, so linear wave theory could be applied.

Orbital velocity. Orbital flow velocities of water particles due to wave motion can be calculated through the derivative of the velocity potential $(\phi)$, which for linear waves is represented by:

$$
\phi(x, z, t)=\frac{\omega H}{2 k} \frac{\cosh k(z+h)}{\sinh k h} \cos (\omega t-k x)
$$

where $z$ represents the vertical distance to a reference plain (e.g. the average water level), $x$ represents the horizontal distance, $t$ is the time and $h$ stands for the (average) water depth. Derivation of this formula for the $x$-direction (i.e. direction of propagation of the waves) results in the instantaneous horizontal velocity component in this direction $(u)$. This instantaneous horizontal velocity depends on the vertical position $z$, the horizontal position $x$ and the time $t$ :

$$
u(x, z, t)=\frac{\partial \phi}{\partial x}=\frac{\cosh k(z+h)}{\sinh k h} \sin (\omega t-k x)
$$

Within the equation of the instantaneous velocity we distinguish between the harmonic component that consists of the final sine term in the equation above and the velocity amplitude $(\hat{U})$, which is constant over time at a certain position:

$$
\hat{U}_{\delta}=\frac{\omega H}{2} \frac{\cosh k(z+h)}{\sinh k h}
$$

Near the bed $(z=-h \rightarrow z+h=0)$ this results in the following equation for the maximum horizontal orbital velocity $\left(\hat{U}_{\delta}\right)$ :

$$
\hat{U}_{\delta}=\frac{\omega H}{2 \sinh k h}
$$

Particle excursion. Wave forces cause an orbital motion of the fluid particles and their excursion (amplitude) can be calculated by integrating the instantaneous velocity, as calculated above, over time. Assuming that both amplitudes in the $x$ - and $y$-directions are negligible compared to $x$ and $z$ (small amplitude waves), this integration yields the following equation for the horizontal particle excursion $(A)$ (van Rijn 2008):

$$
A=\frac{H}{2} \frac{\cosh k(z+h)}{\sinh k h} \cos (\omega t-k x)
$$

Again, we can split this equation into, a harmonic part $(\hat{A})$ and a harmonic part. For the amplitude we find:

$$
\hat{A}=\frac{H}{2} \frac{\cosh k(z+h)}{\sinh k h}
$$

The maximum horizontal excursion of the water particles at the bottom $\left(\hat{A}_{\delta}\right)$ then reads:

$$
\hat{A}_{\delta}=\frac{H}{2 \sinh k h}=\frac{\hat{U}_{\delta}}{\omega}
$$

Bottom friction. The calculation of the wave-related friction coefficient $\left(f_{\mathrm{w}}\right)$ depends on the hydraulic regime that is present, whether it is a laminar, hydraulic smooth or hydraulic rough regime. Each of these regimes comes with its own conditions and method for calculating or approximating the wave-related friction coefficient (van Rijn 2008).

The hydraulic regime is said to be laminar in cases where the following boundary condition applies (van Rijn 2008): 


$$
\hat{U}_{\delta} \hat{A}_{\delta} / v<10^{4}
$$

where $v$ represents the kinematic viscosity, which is about $10^{-6} \mathrm{~m}^{2} \mathrm{~s}^{-1}$ for seawater.

This condition was valid for all experimental conditions and in this case the wave-related friction coefficient can be calculated by Jonsson's (1966) equation:

$$
f_{\mathrm{w}}=2\left(\hat{U}_{\delta} \hat{A}_{\delta} / v\right)^{-0.5}
$$

Bed shear stress. The maximum bed shear stress due to wave propagation $\left(\tau_{\mathrm{b}, \mathrm{w}, \max }\right)$ can subsequently be calculated by:

$$
\tau_{\mathrm{b}, \mathrm{w}, \max }=0.5 \rho f_{\mathrm{w}}\left(\hat{U}_{\delta}\right)^{2}
$$

where $\rho$ represents density. Averaged over the time of half a wave cycle, Eq. (A13) becomes:

$$
\tau_{\mathrm{b}, \mathrm{w}}=0.25 \rho f_{\mathrm{w}}\left(\hat{U}_{\delta}\right)^{2}
$$

Bed shear stresses always add up to zero if averaged over an entire wave cycle due to the oscillatory character of the waves.

\section{Bed shear stresses under flow}

For a constant flow through the flume (instead of waves), the time-averaged flow related bed shear stress $\left(\tau_{\mathrm{b}, \mathrm{c}}\right)$ can be calculated by:

$$
\tau_{\mathrm{b}, \mathrm{c}}=0.125 \rho f_{\mathrm{c}} \bar{v}^{2}
$$

where $f_{\text {c }}$ represents the friction coefficient due to the current and $\bar{v}$ the depth-averaged flow velocity. The friction coefficient from water flow can be calculated from the typical Chézy coefficient $(C)$ for the material and shape of the bottom of the flume:

$$
f_{\mathrm{c}}=8 \frac{g}{C^{2}}
$$

The Chézy coefficient can be calculated from the rough- ness height $k_{\mathrm{s}}$ of the bed material, which is commonly known to be:

$$
C=18 \log \frac{12 h}{k_{\mathrm{s}}}
$$

For the smooth material (glass) of the sides and bottom of the flume, a $k_{\mathrm{s}}$ value of $2 \times 10^{-5} \mathrm{~m}$ was assumed.

\section{Flow and waves}

When the waves and current coincide, the Chézy coefficient is calculated slightly differently:

$$
C=18 \log \frac{12 h}{k_{\mathrm{a}}}
$$

where $k_{\mathrm{a}}$ stands for the apparent roughness height of the bed material (van Rijn 2008). The apparent roughness height can be calculated by:

$$
k_{\mathrm{a}}=k_{\mathrm{s}} \exp \frac{\gamma \hat{U}_{\delta}}{\bar{V}} \quad \text { for } \quad \frac{\hat{U}_{\delta}}{\bar{V}} \leq 5
$$

in which $\gamma$ represents a coefficient accounting for the angle between the flow and the current. For waves following the current, a value of $\gamma=0.75$ should be applied.

In this case, according to van Rijn (2008), the magnitude of the time-averaged total bed shear stress due to currents and waves together $\left(\tau_{\mathrm{b}, \mathrm{cw}}\right)$ can be calculated by:

$$
\left|\tau_{\mathrm{b}, \mathrm{cw}}\right|=\alpha_{\mathrm{r}}\left|\tau_{\mathrm{b}, \mathrm{c}}\right|+\left|\tau_{\mathrm{b}, \mathrm{w}}\right|
$$

with $\alpha_{\mathrm{r}}$ being a reduction factor for the current-induced bed shear stress caused by the presence of the waves:

$$
\begin{aligned}
\alpha_{\mathrm{r}}= & {\left[\ln \left(30 \delta / k_{\mathrm{a}}\right) /\left[\ln \left(30 \delta / k_{\mathrm{s}}\right)\right]^{2}\right.} \\
& {\left[\left\{-1+\ln \left(30 h / k_{\mathrm{s}}\right)\right\} /\left\{-1+\ln \left(30 h / k_{\mathrm{a}}\right)\right\}\right]^{2} }
\end{aligned}
$$

with $\delta$ representing the thickness of the bed boundary layer:

$$
\delta=0.2 \hat{A}_{\delta}\left(\hat{A}_{\delta} / k_{\mathrm{s}}\right)^{-0.25}
$$

Editorial responsibility: Hans Heinrich Janssen, Oldendorf/Luhe, Germany
Submitted: March 3, 2011; Accepted: August 23, 2011 Proofs received from author(s): October 26, 2011 